\title{
Development of Intelligent System for Alert Notification in Indoor Planting
}

\author{
Khairulnur Najiha Abd Karim ${ }^{1}$, Mohd Hudzari Haji Razali ${ }^{*}$, S.M. Shamsi ${ }^{1}$ and \\ Mohamad Noorman Masrek ${ }^{2}$ \\ 1Universiti Teknologi MARA (UiTM), Cawangan Melaka Kampus Jasin, Malaysia \\ najihakarim28@yahoo.com; mariam_shamsi@uitm.edu.my \\ 2Universiti Tecnologi MARA (UiTM), Kampus Puncak Perdana, Malaysia \\ mnoorman@uitm.edu.my \\ *Correspondence: hudzari@uitm.edu.my
}

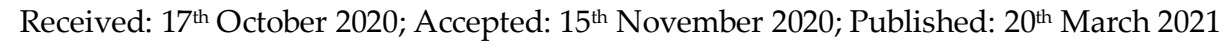

\begin{abstract}
The past decade has seen significant advancement in the field of agriculture industry. Various smart appliances such as cellular phones, moisture sensors, humidity sensor and smart irrigation are set to realize the concept of a new smart farming with the help of latest technology. In Malaysia, farmers experience crop damage and decrease in plant quantity and quality because they unable to monitor the crop all day. The development of a monitoring system that can helps farmer grow crops is enticing demand for busy individuals with physical limitations. Global System for Mobile Communication (GSM) technology, which has emerged in the late 1970s, is an ideal solution for this problem. In this paper, a development of intelligent system for alert notification in indoor planting is presented. This paper describes an application of GSM technology for monitoring light system in indoor planting with the use of hardware component like Arduino board, GSM SIM900A, LDR and LED strip. The major role of this system is to enable farmers to get notified when the light system for their plants is down through GSM SIM900A. Each time the light system is light on and light off, the farmers will receive an SMS to notify them. System functional testing was carried to evaluate the performance of implementing GSM SIM900A whether the prototype is free from error or there are a few errors occurs. The results shown that, the system is well functioning for alert notification in indoor planting monitoring. In conclusion, the development of intelligent systems for alert notification in indoor planting was developed using Arduino and GSM SIM900A to able farmers notified about their indoor planting when to be monitored.
\end{abstract}

Keywords: Arduino; GSM Technology; Intelligent System; Monitoring Indoor Planting

\section{Introduction}

Famous Islamic scholar namely Imam Nawawi Rahmatullah alaih mentioned that the best practice for human being to be involved is agriculture. In agriculture, the very important things are first to get information about soil fertility, second to measure soil moisture content and the third is the analysis of the light needed by plants to ensure healthy growth. Light is one of the most important factors for the growth and development of plants, which in essence is an electromagnetic radiation that can be radiated from a natural or artificial origin. When using artificial light, it is possible to expose and add more interesting features to control plant growth and development [1].

There are different techniques available for supply light to plant that are used other than depend on sunlight. In a modern world, we are trying to introduce and use the new light management techniques to effectively supply light to plants. Automatic light sensor is a replacement for traditional lighting, which is the sunlight. This lighting system will automatically 
turn on when no light is detected while when the system detect light, the light will automatically turn off. Indoor planting is often proposed as a passive approach to air quality improvement [2]. This system is suitable for indoor planting that have limitation to get sunlight.

On the other hand, indoor planting is a way of growing the plants entirely indoors and it is usually related to the greenhouse. This is because this planting method mostly deploys the artificial lights to replace the sunlight and implements some growing methods such as hydroponics to provide the plants nutrients and other basic requirements for growth [3], [4]. This planting method has a significant improvement, then before as the plants and crops are not exposed to the uncontrollable natural environment.

In the past, the common indoor planting system required to setup, the steps for installation is many as well, after all it is required daily monitors to ensure proper growing conditions. When growing plants, pests and bacteria can significantly affect the health of the plants. It will involve environmental predators that can cause harm. To avoid these harmful pests, UV light as a grow light is used in indoor planting [5], [6]. However, UV has its own drawback which is harmful to human skin. That is why LED as grow light is the best tools to use as an artificial sunlight.

It is very important for the owner to manage their plant growth as indoor planting needs different management compare to infield planting [7]. Thus, if the owner has work to do outside from home for more than one day, it will be burdened for them to monitor their light system. The intelligent system for alert notification in indoor planting is developed aims to address the following problems. First, the owner did not alert when their system is breaking down. When the light system for indoor planting is broken down, the plant will be loss source of light. So, the growth of the plant will interrupt, and the yield will also decrease. Second, the labor feels burdened to always supervise and monitor the functionality of the system. A lot of time needed to manually check the light system. For larger industry, labor work to check light system manually is not efficient and contribute to ignorance.

\section{Literature Review}

An innovative IOT-based solution has been developed to monitor soil and environmental conditions for efficient plant production [8]. Developed system equipped with several sensors such as temperature, humidity, NodeMCU soil moisture to monitor plant conditions. In addition, the SMS notification was integrated into the system to inform farmers of the environmental status of the field.

An automated control system that uses IOT-based methods to improve the accuracy of the results and automate crop monitoring, thus reducing human efforts to prevent birds and other animals from the crop [9]. The system used a single fixed camera to detect and track birds and other animals from a real-time video frame using image processing algorithms. A high-frequency sound is produced as soon as the birds and other animals are detected in the video and targeted to push them away from the farm. And an SMS message is sent to the farm owner about the intrusion.

A smart aquaponics system capable of improving fish and plant growth has been proposed [10]. The system was integrated with several units: sensors such as water flow rate, $\mathrm{pH}$, and light intensity, actuators such as water pump, water heater and led light; microcontrollers, and microprocessors for controlling and regulating water quality and light intensity. Early warning automatically sent to the user via e-mail, SMS notification if any irregular condition is detected. At same time, the actuator responds and fixes the irregular condition without manual assistance.

\section{Methodology}

The project methodology that has been chosen is iterative model. In this model, it has five phases. All the activities involve in development process are based on project methodology. Figure 1 shows the exact system flow for development of intelligent systems for alert notification in indoor planting. The system will detect light by using a light dependent resistor (LDR). When the LDR detect light, automatically the LED light strip will turn off. After that, the user will receive messages that informs them that the indoor planting light system is off. 


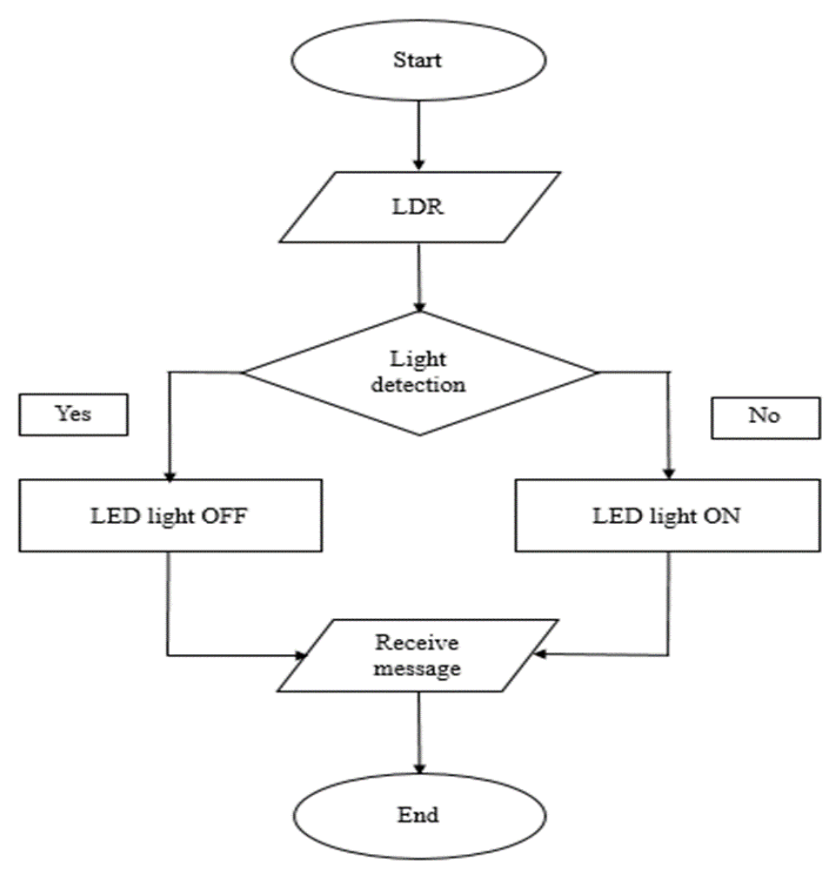

Figure 1. The Flow of the System

Hardware and software requirement are one of the important steps that need to pay attention because without using the suitable hardware and software, the development process might not be able function well and does not support due to software and hardware limitation. In order to prevent this error occurs, thus all the hardware and software requirement that needed for this project are listed as table below. Table 1 with figure 2 showing all configuration and specification used is this project.

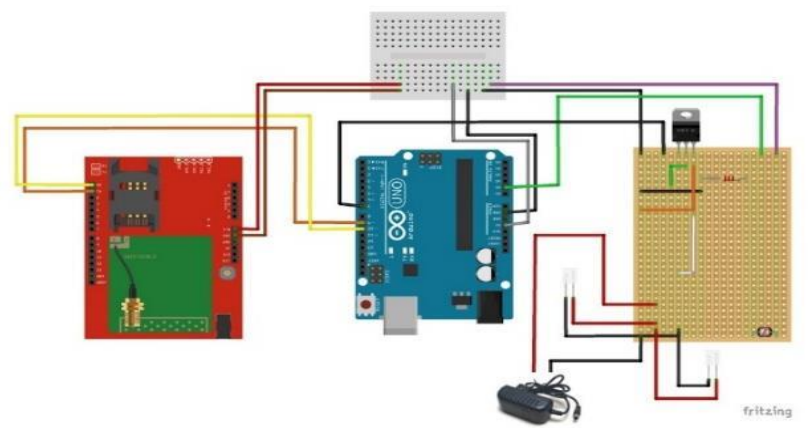

Figure 2. The Complete Connection

Table 1: Hardware and software Requirement Specifications

\begin{tabular}{|l|l|}
\hline Hardware & Specifications \\
\hline CPU & Intel Core i7-4510U \\
\hline RAM & 8GB \\
\hline HDD & $500 \mathrm{~GB}+$ 24G (SSD) \\
\hline Platforms/Operating System & Window 8.1 \\
\hline $\begin{array}{l}\text { Prototype and Program } \\
\text { Development }\end{array}$ & Arduino IDE 1.8.9 \\
\hline Design Connection & Fritzing Software \\
\hline Light Measuring & Lux Light Meter Apps \\
\hline
\end{tabular}

\section{Results and Discussion}

The configuration and connection between Arduino and all the components are the most crucial part as it will lead to the functionality of the system. There are three steps involved in this configuration process. There are connecting Arduino and upload full coding into Arduino board, booting up the GSM SIM900A and connecting pin which are LDR, LED strip and the GSM SIM900A to the Arduino board. The functional testing being conducted after the development and 
implementation has fully completed in order to give more accurate and freer from any error mistake. Functional test required user to evaluate whether the prototype is free from error or there are a few errors occurs [11]. The result of system functional connection and testing are shown in Table 2, respectively.

Table 2: Result of System Functional Testing

\begin{tabular}{|l|l|l|}
\hline \multirow{2}{*}{ Hardware } & \multicolumn{2}{c|}{ User } \\
\cline { 2 - 3 } & Free from error & Error \\
\hline GSM SIM900A & 28 & 2 \\
\hline Receive message & \multicolumn{2}{|}{} \\
\hline LDR & 1 \\
\hline Able to detect light & 29 & 0 \\
\hline LED strip & 30 & \\
\hline Able to emit light &
\end{tabular}

In-lab testing has been made to ensure that the function meets the requirement and do not have errors. The in-lab testing being conducted after the development and implementation was fully completed in order to give more accurate and minimize error [12]. The result of in-lab testing is shown in Figure 3.

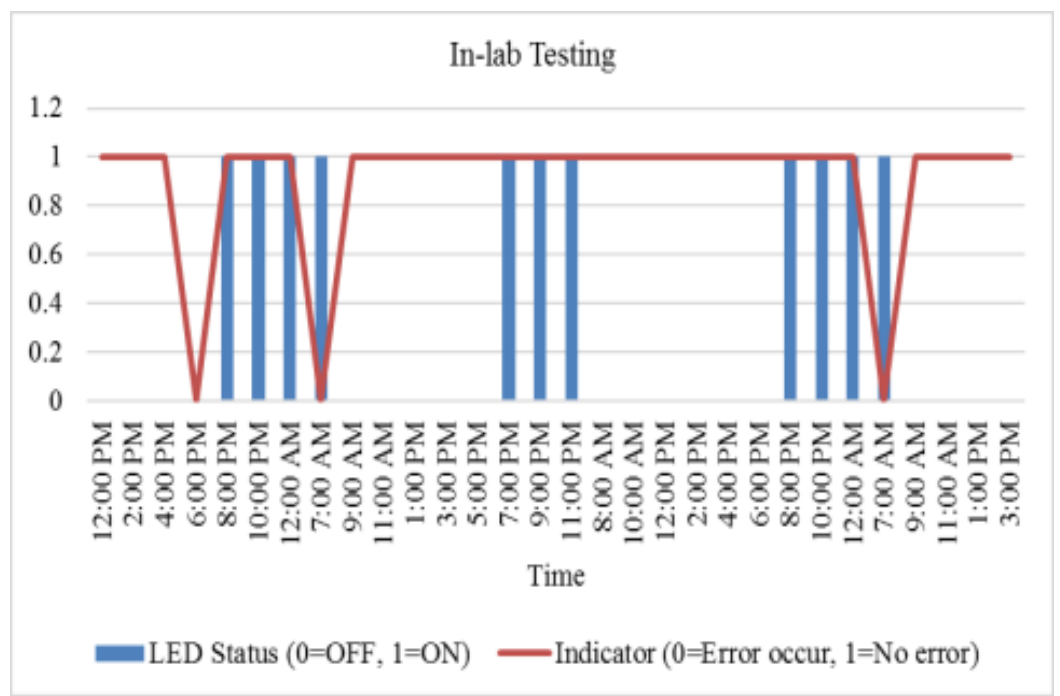

Figure 3. Result of In-lab Testing

Field testing has been conducted in the real indoor planting environment for a week to ensure that the system functions well [13]. The data are collected during the peak time and the attribute recorded include the Lux light meter and the weather at that time. The indications are doing the user receive or not receive the SMS and did the LED strip are light on or light off. The result of field testing is shown in Table 3.

All the hardware requirement and software requirement are useful for developing the intelligent system for alert notification in indoor planting. For the testing, it is divided into two parts which is in-lab testing and field testing. Both testing has been conducted with different environment to evaluate the performance. For the in-lab testing, it is conducted for 30 times randomly while for field testing, it is conducted for a week with a real surrounding environment which is indoor room. The result of the testing has proven that the system is functioning well, and the overall performance is positive. Further related research had been done for a part of development for a new programme syllabus of technology which include in Agro facilities study [14].

Table 3: Result of Field Testing

\begin{tabular}{|l|l|l|l|}
\hline \multirow{2}{*}{ Peak time } & \multicolumn{2}{|l|}{ LED status } & $\begin{array}{l}\text { Average lux } \\
\text { light meter }\end{array}$ \\
\cline { 2 - 4 } & \multicolumn{2}{|l|}{} & \\
\hline $7: 00 \mathrm{AM}$ & $100 \%(7)$ & - & 23.86 \\
\hline $7: 30 \mathrm{AM}$ & - & $100 \%(7)$ & 172.43 \\
\hline $8: 00 \mathrm{AM}$ & - & $100 \%(7)$ & 421.57 \\
\hline $12: 00 \mathrm{PM}$ & - & $100 \%(7)$ & 1887.86 \\
\hline $12: 30 \mathrm{PM}$ & $14.29 \% \quad(1)$ & $85.71 \%(6)$ & 1705.71 \\
\hline
\end{tabular}




\begin{tabular}{|l|l|l|l|}
\hline 1:00 PM & & $100 \%(7)$ & 2251.29 \\
\hline & $14.29 \%(1)$ & $85.71 \%(6)$ & 398.57 \\
\hline $6: 00 \mathrm{PM}$ & & & \\
\hline $7: 30 \mathrm{PM}$ & $14.29 \%(1)$ & $85.71 \%(6)$ & 165.14 \\
\hline $12: 00 \mathrm{PM}$ & $100 \%(7)$ & - & 6.86 \\
\hline $12: 30 \mathrm{AM}$ & $100 \%(7)$ & - & 0 \\
\hline $1: 00 \mathrm{AM}$ & $100 \%(7)$ & - & 0 \\
\hline
\end{tabular}

\section{Conclusion}

In conclusion, an intelligent system for alert notification in indoor planting had been developed in this project. The main goal of this system is to help individual who conduct indoor planting monitoring their light system more convenient and easier. All the objectives mentioned above are achieved by this developed intelligent system for alert notification in indoor planting. In future, many more advance sensors such as water level sensor, oxygen level sensor and actuators should be added to the system in order to make the system more advance in monitoring the indoor planting.

\section{Acknowledgement}

The authors would like to acknowledge the role of ministry of Science, Technology and Innovation for providing grant funding of 100-IRMI/GOV 16/6/2 (025/2019) and the Faculty of Plantation and Agrotechnology at Universiti Teknologi MARA Cawangan Melaka, Jasin Campus in facilitating the field trials and allow to conduct this research.

\section{References}

[1] Omed A. Abbass, David J. Sailor, Elliott T. Gall. Effectiveness of indoor plants for passive removal of indoor ozone, Building and Environment, Volume 119, Pages 62-70, ISSN 0360-1323, July 2017.

[2] Chaudhary, D. D., Nayse, S. P., \& Waghmare, L. M. Application of wireless sensor networks for greenhouse parameter control in precision agriculture. International Journal of Wireless \& Mobile Networks (IJWMN), 3(1), 140-149, February 2011.

[3] De Keyser, E., Dhooghe, E., Christiaens, A., Van Labeke, M. C., \& Van Huylenbroeck, J. LED light quality intensifies leaf pigmentation in ornamental pot plants. Scientia Horticulturae, 253, 270-275, July 2019.

[4] Jacobsson, A., Boldt, M., \& Carlsson, B. A risk analysis of a smart home automation system. Future Generation Computer Systems, 56, 719-733, March 2016.

[5] Flores, K. O., Butaslac, I. M., Gonzales, J. E. M., Dumlao, S. M. G., \& Reyes, R. S. Precision agriculture monitoring system using wireless sensor network and Raspberry Pi local server. In 2016 IEEE region 10 conference (TENCON), pp. 3018-3021, November 2016.

[6] Razali, M. H. H., Roslan, S., Osman, M. R., Othman, M. S., Aspar, Z., \& Abdullah, E. F. H. S. Development of intelligence technique in Shariah compliance washing machine via PLC. Journal of Artificial Intelligence, 10(2), 49-58, 2017.

[7] Chuah, Y. D., Lee, J. V., Tan, S. S., \& Ng, C. K. Implementation of smart monitoring system in vertical farming. In IOP Conference Series: Earth and Environmental Science, Vol. 268, No. 1, p. 012083, IOP Publishing, June 2019.

[8] Abhiram, M. S. D., Kuppili, J., \& Manga, N. A. Smart Farming System using IoT for Efficient Crop Growth. In 2020 IEEE International Students' Conference on Electrical, Electronics and Computer Science (SCEECS), pp. 1-4, February 2020.

[9] Punjabi, H. C., Agarwal, S., Khithani, V., Muddaliar, V., \& Vasmatkar, M. Smart Farming Using IoT. International Journal of Electronics and Communication Engineering and Technology, 8(1), 58-66, 2017.

[10] Kyaw, T. Y., \& Ng, A. K. Smart aquaponics system for urban farming. Energy procedia, 143, 342-347, December 2017.

[11] Matthews, R. B., Rivington, M., Muhammed, S., Newton, A. C., \& Hallett, P. D. Adapting crops and cropping systems to future climates to ensure food security: The role of crop modelling. Global Food Security, 2(1), 24-28, March 2013.

[12] Nissim-Levi, A., Kitron, M., Nishri, Y., Ovadia, R., Forer, I., \& Oren-Shamir, M. Effects of blue and red LED lights on growth and flowering of Chrysanthemum morifolium. Scientia Horticulturae, 254, 77-83, August 2019. 
[13] Ishak, W. W., Hudzari, R. M., \& Tan, M. Y. Development of an Automation and Control Design System for Lowland Tropical Greenhouses. Pertanika Journal of Science and Technology. ISSN, 0128-7680, 2013.

[14] Razali, M. H., Ismail, W. I. W., Ramli, A. R., Sulaiman, M. N., \& Harun, M. H. Development of image based modeling for determination of oil content and days estimation for harvesting of fresh fruit bunches. International Journal of Food Engineering, 5(2), July 2009.

(C) 2021 by the author(s). Published by Annals of Emerging Technologies in Computing (AETiC), under the terms and conditions of the Creative Commons Attribution (CC BY) license which can be accessed at http://creativecommons.org/licenses/by/4.0. 